\title{
The Radioactive Decay Pattern of Blue Topaz TREATED BY NEUTRON IRRADIATION
}

Jian Zhang, Taijin Lu, Manjun Wang, and Hua Chen

A systematic study of 15 neutron-irradiated blue topaz samples was conducted using high-purity germanium (HPGe) digital gamma-ray spectroscopy. The specific activity of the detected radionuclides $\left({ }^{134} \mathrm{Cs}\right.$, ${ }^{182} \mathrm{Ta},{ }^{46} \mathrm{Sc}$, and/or ${ }^{160} \mathrm{~Tb}$ ) was measured, and the decay pattern of the irradiated topaz was determined. Based on the time elapsed since their removal from the nuclear reactor, the amount of time required for the residual radioactivity to decay to safe levels was calculated. Most of the samples were safe at the time of the first measurement (95 days after irradiation), but higher concentrations of radionuclide impurities in some samples will require them to be quarantined for several years.

$\mathrm{R}$ adioactivity is one of the most discussed topics surrounding blue topaz (figure 1), which is commonly treated by irradiation from near-colorless starting material. To maintain consumer confidence, it is important to ensure that these gems do not contain dangerous levels of residual radioactivity. Three major irradiation methods are used: gamma $(\gamma)$, neutron, and electron-beam irradiation (Nassau, 1985; Ashbaugh, 1988). Of these, neutron irradiation creates perhaps the most beautiful medi-

See end of article for About the Authors and Acknowledgments.

Gems \& GemOlogy, Vol. 47, No. 4, pp. 302-307, http://dx.doi.org/10.5741/GEMS.47.4.302.

(C) 2011 Gemological Institute of America um blue color, called "London Blue." Unfortunately, this treatment also produces radioactivity from the nuclides of trace-element impurities in topaz (Crowningshield, 1981; Ashbaugh, 1988), such as Fe, Mn, Co, Zn, Sb, Ta, Cs, Sc, and Tb (Foord et al., 1988; Northrup and Reeder, 1994). These radioactive nuclides, which have various half-lives (table 1), may emit $\gamma$-rays and beta ( $\beta$ ) particles of varying radiation intensity (Ashbaugh, 1991; Nelson, 1991). While a high dose of $\gamma$-rays and $\beta$-particles poses danger, a very low dose is not harmful. Therefore, blue topaz colored by neutron irradiation requires a quarantine period to allow the residual radioactivity to reach a safe level (referred to, e.g., as the exemption level) of less than 74 becquerels per gram $(\mathrm{Bq} / \mathrm{g})$ or 2 nanocuries per gram $(\mathrm{nCi} / \mathrm{g}$; Ashbaugh, 1988).

Investigations of blue topaz have focused mainly on irradiation methods and the cause of the coloration, with less emphasis on the detection of residual radioactivity. Ashbaugh (1988) discussed the radioactivity of colored stones treated by irradiation, as well as potential health hazards and government regulations. Based on these findings, GIA offered testing services for irradiated gems from 1991 through 2006. However, that article did not address blue topaz treated by neutron irradiation. Guo et al. (2000) measured the specific activity of the total alpha $(\alpha)$ and $\beta$ radioactivity of crushed blue topaz after irradiation using an FJ-2603 low-level $\alpha$ - and $\beta$-radiation measuring device and a BH1216A low-background measuring instrument. While that effort was helpful in exploring the radioactive decay of irradiated blue topaz, the specific nuclides involved were not determined. Helal et al. (2006) analyzed the trace elements in topaz samples before and after neutron irradiation using ICP-MS and a high-purity germanium (HPGe) detector. This study proved that radioactivity in blue topaz colored by neutron irradiation is related to variations in the trace elements in the topaz. However, the decay pattern of the radionuclides was unclear. This article studies the residual radioactivity in blue topaz treated by neutron irradiation, identifies the specific radionuclides 

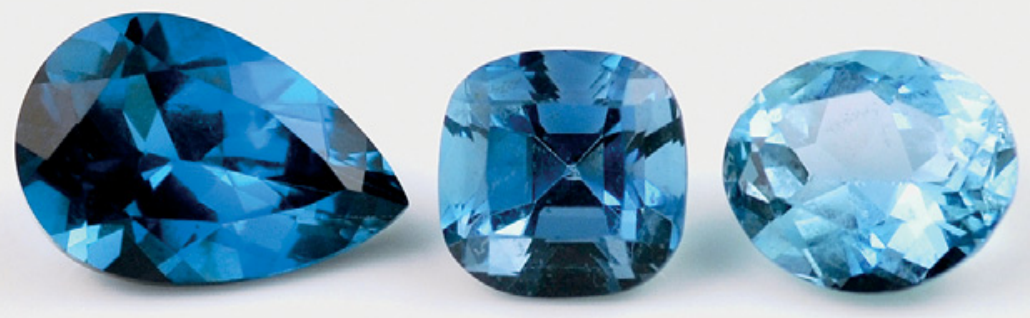

Figure 1. Most blue topaz on the market is irradiated to enhance its color. These stones ( 4-10 ct) were treated by neutron irradiation. Photo by J. Zhang.

TABLE 1. Half-lives of radioactive nuclides in irradiated blue topaz.

\begin{tabular}{cc}
\hline Radionuclide & Half-life (days) \\
\hline${ }^{59} \mathrm{Fe}$ & 44.51 \\
${ }^{2}{ }^{4} \mathrm{Sb}$ & 60.20 \\
${ }^{160} \mathrm{~Tb}$ & 72.30 \\
${ }^{46} \mathrm{Sc}$ & 83.81 \\
${ }^{182} \mathrm{Ta}$ & 114.4 \\
${ }^{65} \mathrm{Zn}$ & 243.8 \\
${ }^{54} \mathrm{Mn}$ & 312.2 \\
${ }^{134} \mathrm{Cs}$ & 753.7 \\
${ }^{60} \mathrm{Co}$ & 1,924 \\
\hline
\end{tabular}

involved, and calculates quarantine periods for the most highly radioactive samples to reach the exemption level.

\section{MATERIALS AND METHODS}

Fifteen samples of cut but unpolished near-colorless topaz (weighing 0.75 to $\sim 2.0 \mathrm{~g}$ ) of pegmatite origin from China's Guangdong Province were studied. EDXRF chemical analy- sis was performed on all 15 samples (after irradiation) and on one additional untreated sample from the same locality, using an ARL Quant'X spectrometer at the National Gemstone Testing Center in Beijing.

The important color centers in topaz are produced after 12 hours of irradiation at $1.2 \times 10^{19}$ neutrons $/\left(\mathrm{cm}^{2} \times \mathrm{sec}\right)$. These conditions were used in this study to produce the colors shown in figure 2. The irradiation was conducted in a "light water" (ordinary water) nuclear reactor at the China Institute of Atomic Energy in Beijing. The samples were placed in cadmium-lined containers to reduce the amount of the thermal neutrons caused by absorption, and also to increase the amount of the fast, color-producing neutrons.

A GEM-30185-Plus Despec HPGe digital gamma-ray spectrometer (figure 3) was used to measure the residual radioactivity of the irradiated blue topaz. The Ge semiconductor detector had a relative efficiency of $25 \%$, an energy resolution of $1.96 \mathrm{keV}$ at $1332.5 \mathrm{keV}$ for ${ }^{60} \mathrm{Co}$, and a peak ratio of 48 . The values measured represent the combined radioactivity of specific nuclides in the process of decay. The measurements were semiquantitative, obtained for 40,000 seconds of active time.

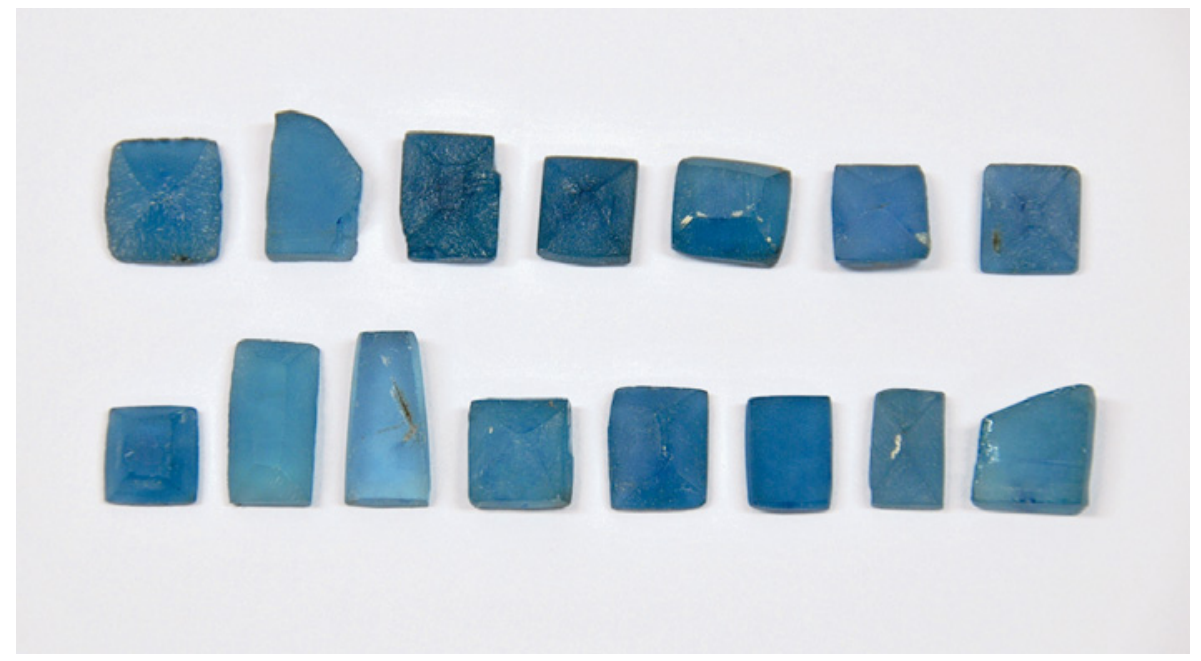

Figure 2. These irradiated topaz samples (weighing 0.75 to $2.0 \mathrm{~g}$ ) were used in this study. From left to right, the top row shows samples numbered Topaz-1 to Topaz7 , and the bottom row shows Topaz-8 to Topaz-15. Photo by I. Zhang. 


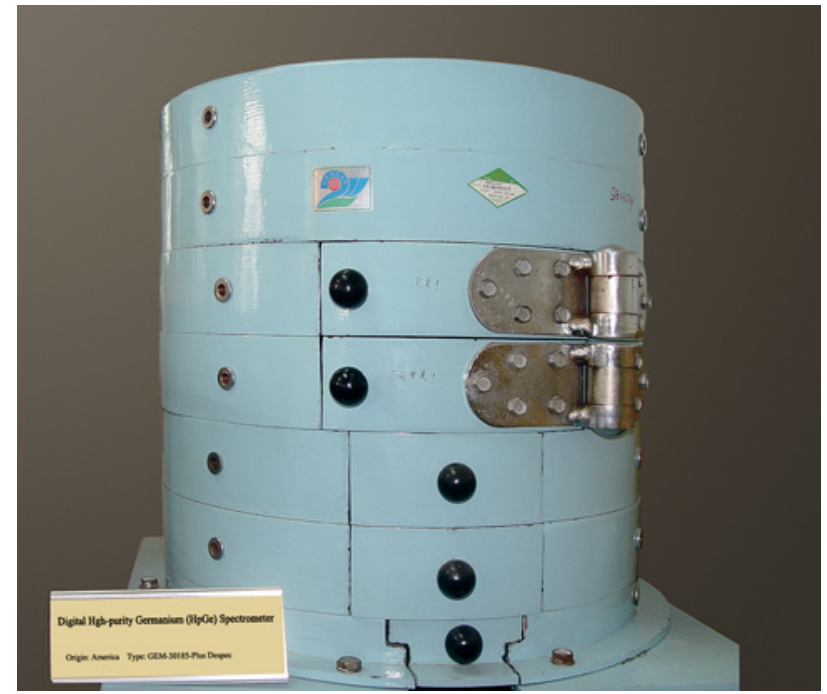

Figure 3. The HPGe digital spectrometer at the China Institute of Atomic Energy in Beijing was used in this study. Photo by J. Zhang.

To explore the decay pattern of the irradiated blue topaz, we conducted four measurements of the residual radioactivity in the 15 samples. The samples were removed from the reactor on September 28, 2005, and gamma-ray spectroscopy was subsequently performed on January 1, 2006 (day 95); March 14 (day 167); April 19 (day 203); and November 30 (day 428). We tested all samples at day 95, and then focused on four samples (figure 4) with residual radioactivity higher than the exemption value (74 Bq/g).

TABLE 2. Residual radioactivity $(\mathrm{Bq} / \mathrm{g})$ of irradiated blue topaz samples after four periods of decay. ${ }^{a}$

\begin{tabular}{llcccc}
\hline \multirow{2}{*}{$\begin{array}{l}\text { Sample } \\
\text { no. }\end{array}$} & \multirow{5}{*}{ Nuclide } & \multicolumn{5}{c}{ Decay time (days) } \\
\cline { 3 - 6 } & & 95 & 167 & 203 & 428 \\
\hline Topaz-8 & ${ }^{134} \mathrm{Cs}$ & 417.6 & 392.1 & 379.2 & 309.3 \\
& ${ }^{182} \mathrm{Ta}$ & 19,800 & 12,800 & 10,290 & 2,668 \\
& Total & 20,218 & 13,192 & 10,669 & 2,977 \\
\hline \multirow{2}{*}{ Topaz-9 } & ${ }^{134} \mathrm{Cs}$ & 1,617 & 1,512 & 1,462 & 1,187 \\
& ${ }^{46} \mathrm{Sc}$ & 296.3 & 162.1 & 120.7 & 18.4 \\
& ${ }^{182} \mathrm{Ta}$ & 495.9 & 321.1 & 258.1 & 66.8 \\
& Total & 2,409 & 1,996 & 1,840 & 1,273 \\
\hline \multirow{4}{*}{ Topaz-10 } & ${ }^{182} \mathrm{Ta}$ & 195,000 & 125,800 & 100,800 & 25,750 \\
& Total & 195,000 & 125,800 & 100,800 & 25,750 \\
\hline \multirow{4}{*}{ Topaz-15 } & ${ }^{134} \mathrm{Cs}$ & 106.2 & 100.2 & 96.5 & 78.7 \\
& $46 \mathrm{Sc}$ & 237.9 & 132.1 & 98.6 & 15.0 \\
& ${ }^{160} \mathrm{~Tb}$ & 3,909 & 1,961 & 1,389 & 160.5 \\
& Total & 4,253 & 2,193 & 1,585 & 254.2 \\
\hline
\end{tabular}

a Although Fe was detected in the samples by EDXRF analysis, no iron radionuclides were detected by gamma-ray spectroscopy.

\section{RESULTS AND DISCUSSION}

EDXRF spectroscopy showed traces of $\mathrm{Mg}, \mathrm{Ca}, \mathrm{Na}, \mathrm{K}$, and $\mathrm{Cl}$ in all samples, while $\mathrm{Fe}, \mathrm{Cs}, \mathrm{Sr}, \mathrm{Sc}, \mathrm{Ta}$, and $\mathrm{Tb}$ were detected in some of them. Gamma-ray spectroscopy revealed the variable presence of four radionuclides in the irradiated topaz: ${ }^{134} \mathrm{Cs},{ }^{182} \mathrm{Ta},{ }^{46} \mathrm{Sc}$, and/or ${ }^{160} \mathrm{~Tb}$ (table 2). When the samples were first tested 95 days after irradiation, four of them showed residual radioactivity above the exemption level. The residual radioactivity of the other 11 samples had decayed below the exemption level or the detection limit of the spectrometer.

\section{NEED TO KNOW}

- Neutron irradiation is commonly used to create an attractive "London Blue" color in near-colorless topaz.

- Topaz may contain trace impurities that become radioactive after neutron irradiation.

- Gamma-ray spectroscopy showed that irradiated topaz samples from China contained up to four radionuclides.

- Most of the samples were safe to handle when measured 95 days after irradiation, but some will require several years to "cool down."

The goal of studying the decay pattern of irradiated blue topaz is to determine the time needed for the residual radioactivity to decay to a safe level (Miraglia, 1986; Miraglia and Cunningham, 1988). The half-life decay formula of radioactive nuclides is necessary for these calculations. De Soete et al. (1972) defined the formula as follows: If the probability of decay for radioactive elements in unit time is $1 / \tau$, and if the number of radioactive elements is $N$, then the number of decayed radioactive elements in the time span of $\mathrm{dt}$ should be $\mathrm{dN}$, where

$$
\mathrm{dN} / \mathrm{N}=-1 / \tau \mathrm{dt}
$$

In formula (1), the negative sign indicates a reduction in the number of subatomic particles that constitute ionizing radiation. Integrating both sides of the equation yields:

$$
\mathrm{N}=\mathrm{N}_{0} \mathrm{e}^{-\mathrm{t} / \tau}
$$

In formula (2), $\mathrm{N}_{0}$ is the original value of radioactivity from a given nuclide, and $\tau$ represents the decay time constant, after which the element has been reduced to $\mathrm{e}^{-1}$ of the original value of radioactivity. The relationship between $\tau$ and half-life $\left(T_{1 / 2}\right)$ can be expressed as:

$$
\mathrm{T}_{1 / 2}=0.693 \tau
$$

Applying formula (3) to formula (2), we can derive the half-life decay formula of radioactive nuclides:

$\mathrm{N}=\mathrm{N}_{0} \mathrm{e}^{-0.693 \mathrm{t} / \mathrm{T}_{1 / 2}}$ 


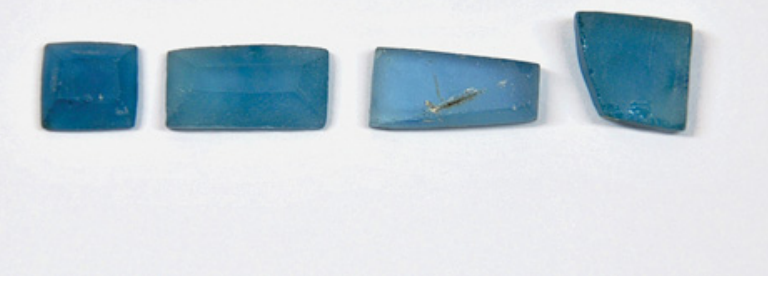

Figure 4. These four samples (9.5-16.5 mm long) had residual radioactivity higher than the exemption level when initially measured after 95 days. From left to right: Topaz-8, Topaz-9, Topaz-10, and Topaz-15. Photo by J. Zhang.

In formula (4), $\mathrm{N}_{0}$ is the initial value of radioactivity and $\mathrm{N}$ is the unknown value of radioactivity, expressed in units of Bq. $\mathrm{T}_{1 / 2}$ is the half-life of the nuclide, and $\mathrm{t}$ is its decay time.

The specific activity of each radionuclide present in a given sample was calculated. The values obtained at the first stage of radiation detection (after 95 days) can be set as the initial values. Values for each subsequent stage can then be calculated and compared with the detected values, as shown in table 3 . In addition, the radioactivity of the samples upon their removal from the reactor (day 0) can be calculated. Most importantly, the time required for the residual radioactivity to decay below the exemption level $(74 \mathrm{~Bq} / \mathrm{g}$ ) can be derived using the formula; these times are shown in table 4 for the four samples.

\section{CONCLUSIONS}

Blue topaz (e.g., figure 5) typically takes two to three years to decay below the exemption level after neutron irradiation. The actual quarantine time necessary for specific samples depends on several factors. There are three scenarios that can contribute to high levels of residual radioactivity in irradiated gems.

The first is the presence of activated impurities with a long half-life (i.e., a comparatively slow rate of decay). For example, ${ }^{134} \mathrm{Cs}$ has a half-life of 2.06 years. This radionuclide was present in three of the four topaz samples showing residual radioactivity, and for Topaz- 9 the time required to decay below the exemption level was calculated at 3,440 days ( 9.4 years).

Second, high concentrations of activated impurities (even those that do not have a long half-life) may produce high residual radioactivity. Sample Topaz-10, for example, contained a large amount of ${ }^{182} \mathrm{Ta}$ (half-life of 114 days). Consequently, the sample's radioactivity upon removal from the reactor was $347,600 \mathrm{~Bq} / \mathrm{g}$, and it took 1,391 days ( 3.8 years) for the sample to decay below the exemption level.

The third scenario contributing to high levels of residual

TABLE 3. Detected and calculated specific activity $(\mathrm{Bq} / \mathrm{g})$ of radionuclides in irradiated blue topaz.

\begin{tabular}{|c|c|c|c|c|c|c|c|}
\hline \multirow{2}{*}{ Sample no. } & \multirow{2}{*}{ Nuclide } & \multirow{2}{*}{ Method } & \multicolumn{5}{|c|}{ Decay time (days) } \\
\hline & & & 0 & 95 & 167 & 203 & 428 \\
\hline \multirow[t]{4}{*}{ Topaz-8 } & \multirow[t]{2}{*}{${ }^{134} \mathrm{Cs}$} & Detected & & 417.6 & 392.1 & 379.2 & 309.3 \\
\hline & & Calculated & 455.8 & & 390.8 & 378.0 & 307.2 \\
\hline & \multirow[t]{2}{*}{${ }^{182} \mathrm{Ta}$} & Detected & & 19,800 & 12,800 & 10,290 & 2,668 \\
\hline & & Calculated & 35,280 & & 12,780 & 10,270 & 2,664 \\
\hline \multirow[t]{6}{*}{ Topaz-9 } & \multirow[t]{2}{*}{${ }^{134} \mathrm{Cs}$} & Detected & & 1,617 & 1,512 & 1,462 & 1,187 \\
\hline & & Calculated & 1,764 & & 1,513 & 1,464 & 1,190 \\
\hline & \multirow[t]{2}{*}{${ }^{46} \mathrm{SC}$} & Detected & & 296.3 & 162.1 & 120.7 & 18.4 \\
\hline & & Calculated & 650.0 & & 163.4 & 121.3 & 18.9 \\
\hline & \multirow[t]{2}{*}{${ }^{182} \mathrm{Ta}$} & Detected & & 495.9 & 321.1 & 258.1 & 66.8 \\
\hline & & Calculated & 877.7 & & 320.1 & 257.2 & 66.5 \\
\hline \multirow[t]{2}{*}{ Topaz-10 } & \multirow[t]{2}{*}{${ }^{182} \mathrm{Ta}$} & Detected & & 195,000 & 125,800 & 100,800 & 25,750 \\
\hline & & Calculated & 347,600 & & 125,900 & 101,100 & 25,770 \\
\hline \multirow[t]{6}{*}{ Topaz-15 } & \multirow[t]{2}{*}{${ }^{134} \mathrm{Cs}$} & Detected & & 106.2 & 100.2 & 96.5 & 78.7 \\
\hline & & Calculated & 115.7 & & 99.2 & 96.0 & 78.0 \\
\hline & \multirow[t]{2}{*}{${ }^{46} \mathrm{SC}$} & Detected & & 237.9 & 132.1 & 98.6 & 15.0 \\
\hline & & Calculated & 521.8 & & 131.1 & 97.4 & 15.1 \\
\hline & \multirow[t]{2}{*}{${ }^{160} \mathrm{~Tb}$} & Detected & & 3,909 & 1,961 & 1,389 & 160.5 \\
\hline & & Calculated & 9,717 & & 1,960 & 1,388 & 160.6 \\
\hline
\end{tabular}


TABLE 4. Decay time needed for irradiated blue topaz samples to reach the exemption level of $74 \mathrm{~Bq} / \mathrm{g}$.

\begin{tabular}{|c|c|c|c|c|c|c|c|c|}
\hline \multirow{2}{*}{ Sample no. } & \multirow{2}{*}{ Nuclide } & \multicolumn{7}{|c|}{ Decay time (days) } \\
\hline & & 0 & 95 & 428 & 703 & 1,391 & 1,975 & 3,440 \\
\hline \multirow[t]{3}{*}{ Topaz-8 } & ${ }^{134} \mathrm{Cs}$ & 455.8 & 417.6 & 309.3 & 238.4 & 139.8 & 73.8 & \\
\hline & ${ }^{182} \mathrm{Ta}$ & 35,280 & 19,800 & 2,668 & 491.5 & 14.5 & 0.2 & \\
\hline & Total & 35,736 & 20,218 & $2,997.3$ & 729.9 & 154.3 & 74.0 & \\
\hline \multirow[t]{4}{*}{ Topaz-9 } & ${ }^{134} \mathrm{Cs}$ & 1,764 & 1,617 & $1,187.3$ & 922.5 & 540.7 & 285.6 & 74.0 \\
\hline & ${ }^{46} \mathrm{Sc}$ & 650.0 & 296.3 & 18.4 & 1.9 & 0 & 0 & 0 \\
\hline & ${ }^{182} \mathrm{Ta}$ & 877.7 & 495.9 & 66.8 & 12.2 & 0.4 & 0 & 0 \\
\hline & Total & 3,291 & 2,409 & 1,272 & 936.6 & 541.1 & 285.6 & 74.0 \\
\hline \multirow[t]{2}{*}{ Topaz-10 } & ${ }^{182} \mathrm{Ta}$ & 347,600 & 195,000 & 25,750 & 4,843 & 73.9 & & \\
\hline & Total & 347,600 & 195,000 & 25,750 & 4,843 & 73.9 & & \\
\hline \multirow[t]{4}{*}{ Topaz-15 } & ${ }^{134} \mathrm{Cs}$ & 115.7 & 106.2 & 78.7 & 60.5 & & & \\
\hline & ${ }^{46} \mathrm{Sc}$ & 521.8 & 237.9 & 15.0 & 1.6 & & & \\
\hline & ${ }^{160} \mathrm{~Tb}$ & 9,717 & 3,909 & 160.5 & 11.5 & & & \\
\hline & Total & 10,350 & 3,434 & 254.2 & 73.6 & & & \\
\hline
\end{tabular}

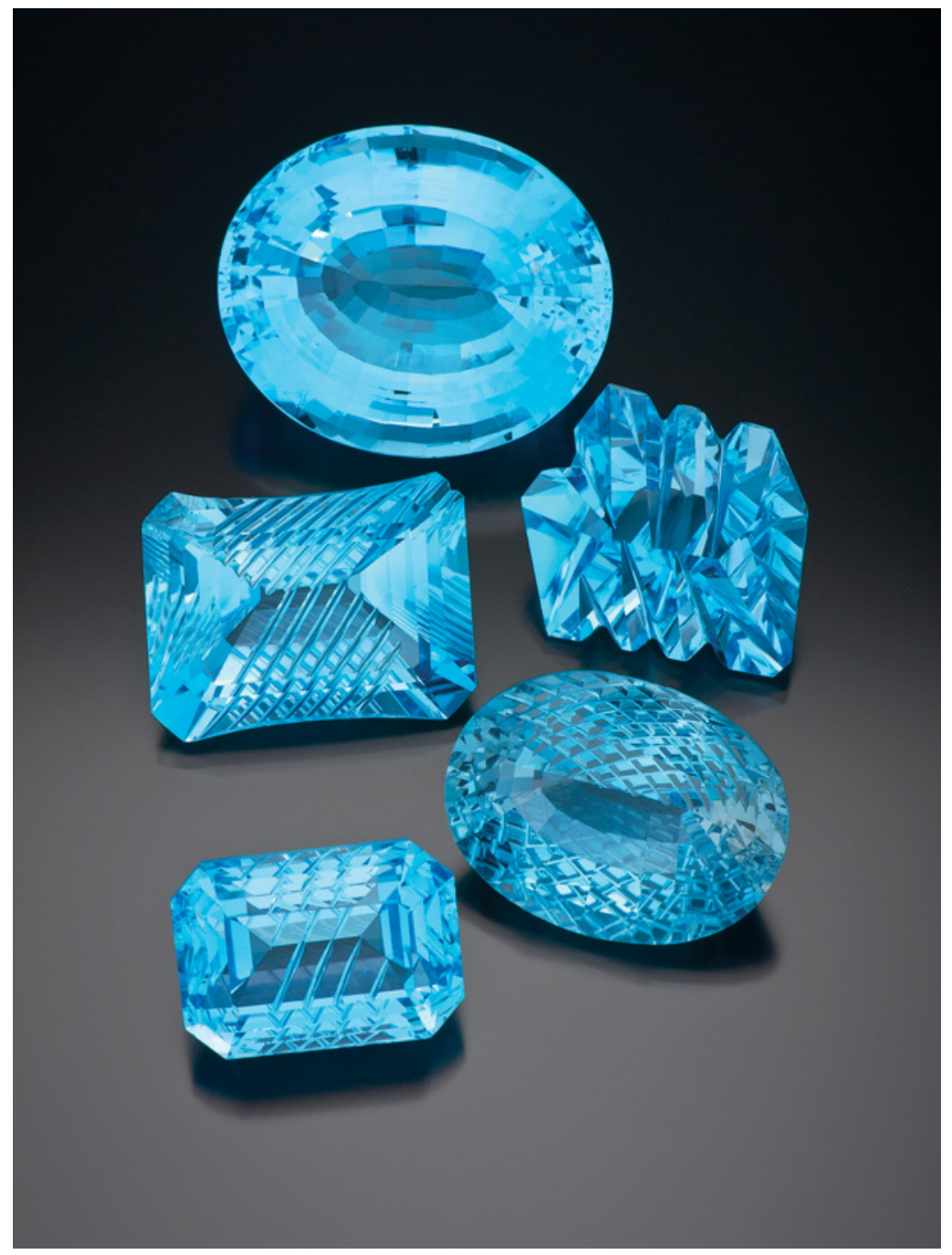

radioactivity is the presence of activated impurities with a long half-life combined with relatively high concentrations.

The Chinese topaz studied for this article should be assumed to contain different trace-element impurities than starting material from other sources (e.g., Brazil), and therefore the decay times presented in this study are not representative of all neutronirradiated topaz on the market. Still, the procedure and data presented here provide useful information for evaluating the residual radioactivity in topaz treated by neutron irradiation, regardless of locality.

Figure 5. Treated blue topaz (here, 85.79-243.66 ct) is commonly encountered in the global gem market, and neutron-irradiated samples must undergo appropriate safeguards to ensure that they do not contain dangerous levels of residual radioactivity. Photo by Robert Weldon; from top to bottom, GIA Collection nos. 16203, 30886, 31942, 30889, and 31947. 


\section{ABOUT THE AUTHORS}

Mr. Zhang (zj7975@sina.com) is an engineer, Dr. Lu is chief researcher, Ms. Wang is a professor, and Ms. Chen is director of the research department, at the National Gems \& Jewellery Technology Administrative Center, in Beijing, China.

\section{ACKNOWLEDGMENTS}

The authors thank Ms. Xiuqing Gao for irradiating the topaz samples, and Mr. Yongbao Gao for performing the gamma-ray spectroscopy; both are located at the China Institute of Atomic Energy in Beijing.

\section{REFERENCES}

Ashbaugh C.E. (1988) Gemstone irradiation and radioactivity. GÆG, Vol. 24, No. 4, pp. 196-213, http://dx.doi.org/10.5741/ GEMS.24.4.196.

Ashbaugh C.E. III (1991) Radioactive and radiation treated gemstones. Radioactivity « Radiochemistry, Vol. 2, No. 1, pp. $42-57$.

Crowningshield R. (1981) Irradiated topaz and radioactivity. GÆ)G, Vol. 17, No. 4, pp. 215-217, http://dx.doi.org/10.5741/ GEMS.17.4.215.

Foord E.E., Jackson L.L., Taggart J.E., Crock J.G., King T.V.V. (1988) Topaz: Environments of crystallization, crystal chemistry, and infrared spectra. Mineralogical Record, Vol. 26, pp. 69-70.

Guo Y.C., Liu X.L., Huang J.Z. (2000) Radioactivity and decay pattern of topaz colored by neutron radiation. China Occupational Medicine, Vol. 27, No. 2, pp. 19-21 [in Chinese].

Helal A.I., Zahran N.F., Gomaa M.A.M., Salama S. (2006)
Irradiated topaz in the reactor. VIII Radiation Physics 4 Protection Conference, Beni Suef - Fayoum, Egypt, November $13-15$, pp. 447-451.

Miraglia F.J. (1986) Distribution of Products Irradiated in Research Reactors. U.S. Nuclear Regulatory Commission Generic Letter 86-11, June 25.

Miraglia F.J., Cunningham R.E. (1988) Distribution of Gems Irradiated in Research Reactors. U.S. Nuclear Regulatory Commission Generic Letter 88-04, February 23.

Nassau K. (1985) Altering the color of topaz. GÆ G, Vol. 21, No. 1, pp. 26-34, http://dx.doi.org/10.5741/GEMS.21.1.26.

Nelson K.L. (1991) Health Risk Assessment of Irradiated Topaz. Unpublished $\mathrm{PhD}$ thesis, University of Minnesota.

Northrup P.A., Reeder R.J. (1994) Evidence for the importance of growth-surface structure to trace element incorporation in topaz. American Mineralogist, Vol. 79, pp. 1167-1175.

de Soete D., Gijbels R., Hoste J. (1972) Neutron Activation Analysis. John Wiley \& Sons, New York.

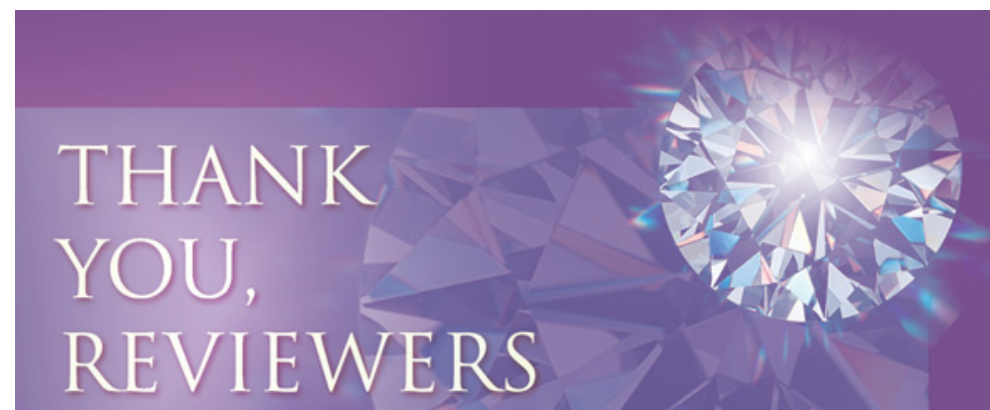

GEMS \& GEMOLOGY requires that all articles undergo a peer review process in which each manuscript is evaluated by at least three experts in the field. This process is vital to the accuracy and readability of the published article. Because members of our Editorial Review Board cannot have expertise in every area, we sometimes call on other experts to share their intellect and insight. In addition to the members of our Editorial Review Board, we extend a heartfelt thanks to the following individuals who reviewed manuscripts for G\&G in 2010-2011.
Dr. Ilaria Adamo Dr. Vladimir Balitsky Dudley Blauwet Bill Boyajian Dr. Christopher M. Breeding Maggie Campbell-Pedersen * Dr. Francois Farges Dr. David Fisher Dr. Harald Gabasch Dr. Eloïse Gaillou Rui Galopim de Carvalho Al Gilbertson Dr. Gaston Giuliani Dr. Lee Groat Dr. John Gurney Thomas Hainschwang Hertz Hasenfeld Richard Hughes Dr. Stefanos Karampelas John King William Larson Elise Misiorowski Vincent Pardieu Dr. Adolf Peretti Dr. Federico Pezzotta John Pollard Dr. Ilene Reinitz Dr. Benjamin Rondeau Dr. Andy Shen Russell Shor Elisabeth Strack Carol Stockton Ursula Wehrmeister 